Article

\title{
New Terpendole Congeners, Inhibitors of Sterol O-Acyltransferase, Produced by Volutella citrinella BF-0440
}

\author{
Elyza Aiman Azizah Nur ${ }^{1}$, Keisuke Kobayashi ${ }^{1,2}$, Ai Amagai ${ }^{3}$, Taichi Ohshiro ${ }^{1,3,4}$ \\ and Hiroshi Tomoda ${ }^{1,2,3, *}$ \\ 1 Department of Microbial Chemistry, Graduate School of Pharmaceutical Sciences, Kitasato University, \\ Tokyo 108-8641, Japan; ml18124@st.kitasato-u.ac.jp (E.A.A.N.); kobayashikei@pharm.kitasato-u.ac.jp (K.K.); \\ tohshiro@med.nagoya-u.ac.jp (T.O.) \\ 2 Medicinal Research Laboratories, School of Pharmacy, Kitasato University, Tokyo 108-8641, Japan \\ 3 Department of Microbial Chemistry, School of Pharmacy, Kitasato University, Tokyo 108-8641, Japan; \\ pp14007@st.kitasato-u.ac.jp \\ 4 ITOCHU Collaborative Research-Molecular Targeted Cancer Treatment for Next Generation, \\ Graduate School of Medicine, Nagoya University, Aichi 466-8550, Japan \\ * Correspondence: tomodah@pharm.kitasato-u.ac.jp
}

Received: 16 June 2020; Accepted: 3 July 2020; Published: 6 July 2020

check for updates

\begin{abstract}
New terpendoles N-P (1-3) were isolated along with 8 structurally related known compounds including terpendoles and voluhemins from a culture broth of the fungus Volutella citrinella BF-0440. The structures of 1-3 were elucidated using various spectroscopic experiments including 1D- and 2D-NMR. All compounds 1-3 contained a common indole-diterpene backbone. Compounds 2 and 3 had 7 and 6 consecutive ring systems with an indole ring, respectively, whereas 1 had a unique indolinone plus 4 consecutive ring system. Compounds 2 and 3 inhibited both sterol $O$-acyltransferase 1 and 2 isozymes, but 1 lost the inhibitory activity. Structure-activity relationships of fungal indole-diterpene compounds are discussed.
\end{abstract}

Keywords: terpendole; sterol O-acyltransferase; SOAT; inhibitor; fungal metabolite

\section{Introduction}

Natural compounds derived from animals, plants, and microbes have historically been used as a rich source for new drug discovery. These sources provide more structurally diversity than synthetic compounds [1]. Generally, a set of structurally related compounds tend to be produced by a single organism, allowing us to identify and associate the chemical groups responsible for evoking a target biological effect. This structure-activity relationship (SAR) information then becomes a key approach for lead optimization in drug discovery.

Sterol $O$-acyltransferase (SOAT), an enzyme that catalyzes the formation of cholesteryl ester (CE), has been a potential target for development as a post-statin drug. Researchers now understand that SOAT has two isozymes, SOAT1 and SOAT2, with distinct functions in the human body [2-5], and that selective inhibition of SOAT2 is responsible for the prevention of atherosclerosis and fatty liver disease [6-10]. Accordingly, our group has been focusing on the search for SOAT2 selective inhibitors from microbial resources. As a result, we found that fungal pyripyropene A was a highly selective SOAT2 inhibitor [11]. After this finding, we continued screening microbial culture broths for SOAT2 inhibitors, but the hit rate was very low. Recently, we discovered new indoline-diterpene-containing compounds, termed voluhemins A (4) and B (5), and NK12838 (6) [12], from culture broth of the fungus Volutella citrinella BF-0440 [13]. Notably, 5 was found to be a selective SOAT2 inhibitor. Furthermore, 
the culture broth of the fungus still contained other structurally related compounds. As a result, new terpendoles N-P (1-3), were isolated from the culture broth along with four known terpendoles (7-10) [14,15] and tolypocladin A (11) [16] and presented in Figure 1. In the present study, we describe the isolation, structural elucidation, and SOAT inhibitory activity of these compounds and discussed the SARs of indole/indoline-diterpenes in SOAT1/SOAT2 inhibitory activity.

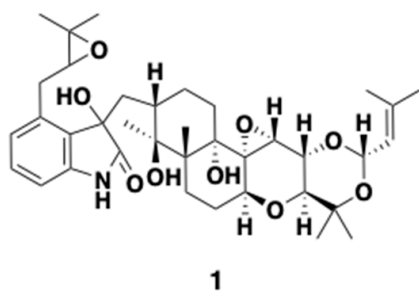

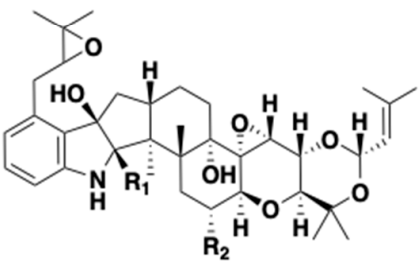

4: $\mathbf{R}_{1}=\mathrm{OH}, \quad \mathbf{R}_{2}=\mathbf{H}$ 5: $\mathbf{R}_{1}=\mathrm{OCH}_{3}, \mathbf{R}_{2}=\mathrm{H}$ 6: $\mathbf{R}_{1}=\mathrm{OH}, \quad \mathbf{R}_{2}=\mathrm{OH}$

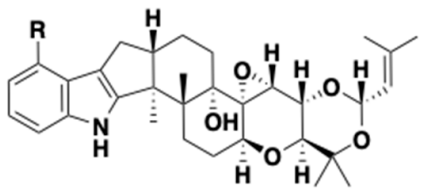<smiles>[3H]C=C(C)C</smiles>

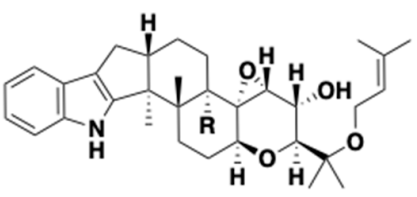

8: $\mathbf{R}=\mathbf{H}$ 11: $R=O H$

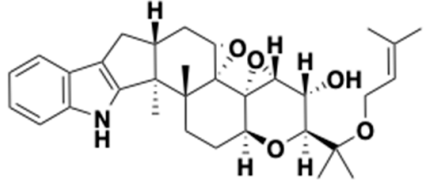

3
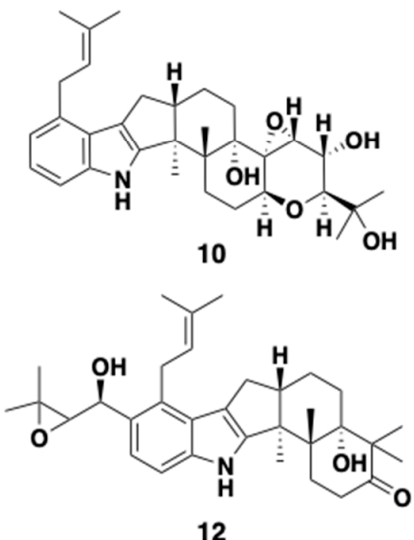

Figure 1. Structures of terpendoles and other known compounds: Terpendole $\mathrm{N}(\mathbf{1})$, terpendole $\mathrm{O}(\mathbf{2})$, terpendole P (3), voluhemin A (4), voluhemin B (5), NK12838 (6), terpendole C (7), terpendole D (8), terpendole L (9), tolypocladin A (10), terpendole J (11), and sespendole (12).

\section{Results}

\subsection{Isolation of New Terpendoles and Related Compounds}

The isolation procedure of new terpendoles (1-3) and known related compounds (4-11) from $V$. citrinella BF-0440 culture broth is summarized in Figure 2. The crude extract (2.5 g) was fractionated by an ODS column with stepwise gradient elution ( $40 \%$ aq $\mathrm{CH}_{3} \mathrm{CN}, 60 \%$ aq $\mathrm{CH}_{3} \mathrm{CN}, 80 \%$ aq $\mathrm{CH}_{3} \mathrm{CN}_{\text {, }}$ and $100 \% \mathrm{CH}_{3} \mathrm{CN}$ solutions, fractionated into two). Voluhemins $\mathrm{A}(4)$ and $\mathrm{B}$ (5) were purified from fraction $80 \%-1$, as reported in detail previously [13]. Fraction 60\%-2 (249 mg) was subjected to preparative high-performance liquid chromatography (HPLC) to give NK12838 (6) [12] and new terpendole N (1). Purification from fraction $80 \%-2(214 \mathrm{mg})$ by preparative HPLC allowed isolation of three peaks, new terpendole $\mathrm{O}(2)$, terpendole $C$ (7) [14], and a third peak. The third peak was, however, found to be a mixture of related compounds from proton NMR analyses. This mixture was also obtained from fraction 100\%-1 (662 mg) by preparative HPLC along with terpendoles C (7) [14], $\mathrm{D}$ (8) [14], and L (9) [15], and tolypocladin A (10) [16]. The mixture was finally separated in different HPLC conditions to yield a new terpendole P (3) and a known terpendole J (11) [15]. All of these peaks were collected and concentrated to dryness to give $1(2.1 \mathrm{mg}), 2(21.6 \mathrm{mg}), 3(2.7 \mathrm{mg}), 6(46.6 \mathrm{mg})$, 7 (29.7 $\mathrm{mg}$ and $15.7 \mathrm{mg}$ from 80\%-2 and 100\%-1, respectively), 8 (8.3 mg), 9 (6.8 mg), 10 (3.8 mg) and 11 $(1.6 \mathrm{mg})$ as white powders. 


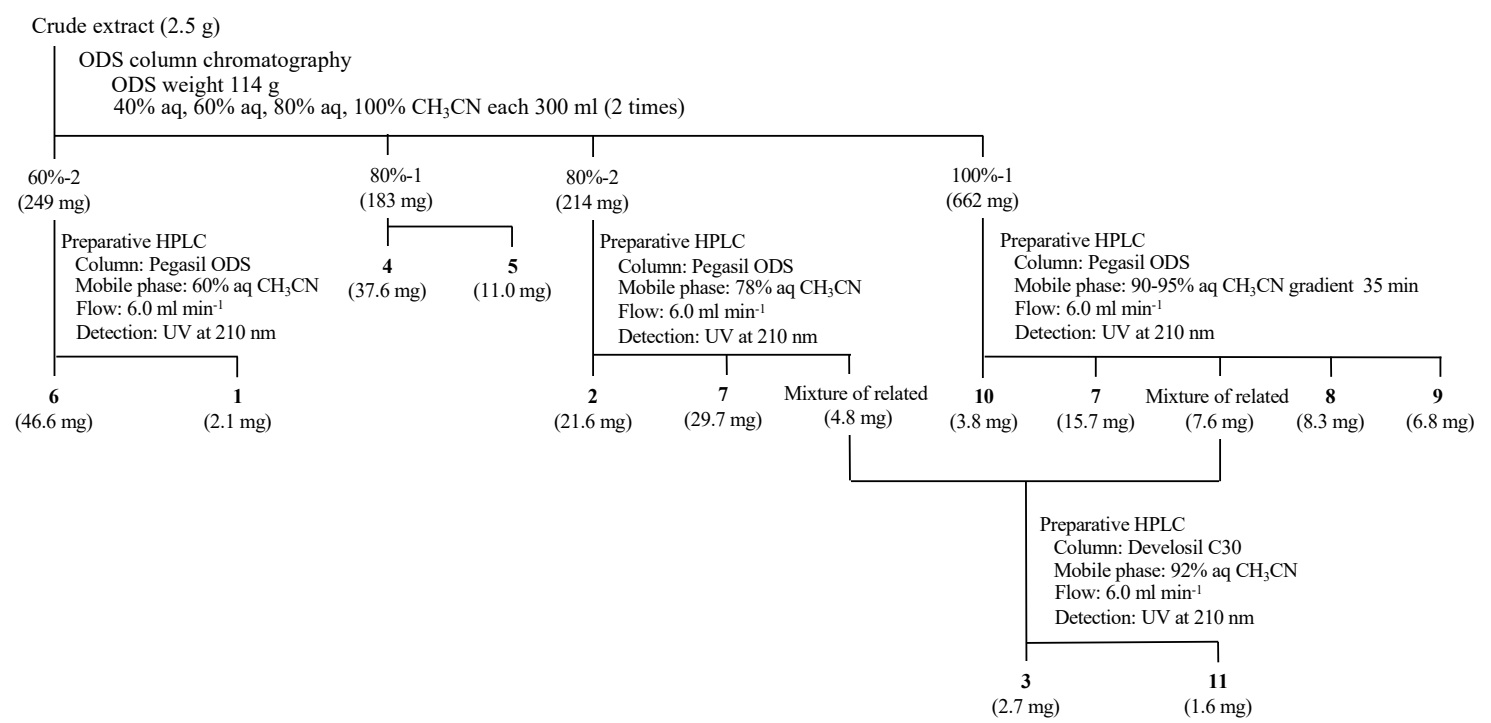

Figure 2. Isolation procedure of terpendoles.

\subsection{Structural Elucidation of New Terpendole O (2)}

The physicochemical properties of 2 are summarized in Table 1. The molecular formula $\mathrm{C}_{37} \mathrm{H}_{49} \mathrm{NO}_{6}$ of 2 was determined based on HR-ESIMS $\left(\mathrm{m} / \mathrm{z}\right.$, found 604.3638 , calcd 604.3625 for $\left.\mathrm{C}_{37} \mathrm{H}_{50} \mathrm{NO}_{6}[\mathrm{M}+\mathrm{H}]^{+}\right)$, indicating 14 degrees of unsaturation. The characteristic UV absorbance maxima at $230 \mathrm{~nm}$ and $283 \mathrm{~nm}$, along with IR absorptions at 3449, 2979, 2930, and $1458 \mathrm{~cm}^{-1}$, were similar to those of reported terpendoles [14,15], suggesting 2 possesses a similar chemical skeleton. The structure of 2 was then elucidated using NMR experiments (Figures S1-S12). The data from ${ }^{13} \mathrm{C}-\mathrm{NMR}$ and ${ }^{1} \mathrm{H}-\mathrm{NMR}$ in DMSO- $d_{6}$ are shown in Table 2 . The ${ }^{13} \mathrm{C}$-NMR spectrum of 2 showed 37 resolved signals, which were classified into 8 methyl carbons, 6 methylene carbons, four $s p^{2}$ methine carbons, $7 s p^{3}$ methine carbons, $6 s p^{2}$ quaternary carbons, and $6 s p^{3}$ quaternary carbons using an analysis of heteronuclear single-quantum correlation (HSQC) data (Table 2 and Figure S2). The ${ }^{1} \mathrm{H}-\mathrm{NMR}$ spectrum of 2 showed 49 proton signals (Table 2 and Figure S1), which were classified into 8 methyl protons, 6 methylene protons, four $s p^{2}$, and $7 s p^{3}$ methine protons, one amine proton and one hydroxy proton. The connectivity of proton and carbon atoms was established using HSQC (Table 2). These data are in accordance with the molecular formula. As shown in Figure $3 \mathrm{a}$, analysis of the ${ }^{1} \mathrm{H}-{ }^{1} \mathrm{H}$ correlation spectroscopy (COSY) spectrum gave 6 partial structures I to VI; (I) $5-\mathrm{H}_{2}(\delta 1.67,2.42), 6-\mathrm{H}(\delta 2.12)$ and $7-\mathrm{H}(\delta 4.26)$, (II) 9-H $(\delta$ $3.40), 10-\mathrm{H}(\delta 4.04)$ and $11-\mathrm{H}(\delta 3.50),(\mathrm{III}) 14-\mathrm{H}(\delta 1.46,1.52), 15-\mathrm{H}_{2}(\delta 1.46,1.80), 16-\mathrm{H}(\delta 2.71)$ and $17-\mathrm{H}_{2}(\delta 2.45,2.71),(\mathrm{IV}) 21-\mathrm{H}(\delta 6.71), 22-\mathrm{H}(\delta 6.86)$ and $23-\mathrm{H}(\delta 7.12),(\mathrm{V}) 31-\mathrm{H}(\delta 5.50)$, and $33-\mathrm{H}(\delta$ $5.10)$, and $(\mathrm{VI}) 37-\mathrm{H}_{2}(\delta 2.93,3.01)$, and $38-\mathrm{H}(\delta 2.93)$. The COSY correlations of $14-\mathrm{H}_{2}(\delta 1.43,1.56)$ and $15-\mathrm{H}_{2}(\delta 1.60,1.90)$, and $37-\mathrm{H}_{2}(\delta 2.98,3.29)$ and $38-\mathrm{H}(\delta 3.09)$ were more clearly observed in $\mathrm{CDCl}_{3}$ (Table S1 and Figure S10). Furthermore, the following linkages including partial structures I to VI were elucidated using ${ }^{13} \mathrm{C}-{ }^{1} \mathrm{H}$ long range couplings of ${ }^{2} \mathrm{~J}$ and ${ }^{3} \mathrm{~J}$ in the heteronuclear multiple bond correlation (HMBC) spectrum (Figure 3a). (1) The cross peaks from 21-H and 23-H to C-19 ( $\delta 124.1)$ and from $22-\mathrm{H}$ to $\mathrm{C}-20(\delta 128.0)$ and $\mathrm{C}-24(\delta 139.7)$ indicated the presence of a trisubstituted benzene ring containing partial structure IV. The cross peaks from 1-NH $(\delta 10.69)$ to C-2 ( $\delta 152.3), \mathrm{C}-18(\delta 114.3)$, C-19, and C-24 indicated that a pyrrole ring is directly attached to the benzene, showing the presence of an indole moiety. (2) The cross peaks from $37-\mathrm{H}_{2}(\delta 2.93,3.01)$ to $\mathrm{C}-39(\delta 57.9)$, from $40-\mathrm{H}_{3}(\delta 18.7)$ to C-38 ( $\delta 63.4), C-39$, and C-41 $(\delta 24.6)$ and from $41-\mathrm{H}_{3}(\delta 24.6)$ to C-38, C-39, and C-40 suggested the presence of an isopentanyl unit containing partial structure VI. Taking the chemical shifts of C-38 and $\mathrm{C}-39$ into consideration, these carbons were involved in the formation of an epoxide moiety. The cross peaks from $21-\mathrm{H}$ to $\mathrm{C}-37(\delta 32.3)$ and from $38-\mathrm{H}$ to $\mathrm{C}-20$ supported that an epoxy-isopentanyl unit is connected to C-20 of the indole moiety. (3) The cross peaks from $17-\mathrm{H}_{2}$ to $\mathrm{C}-2, \mathrm{C}-3(\delta 49.9)$, and C-18 suggested that a cyclopentene ring (ring A) is attached to the indole ling. (4) The cross peaks from 
$25-\mathrm{H}_{3}(\delta 1.16)$ to $\mathrm{C}-3$ and $\mathrm{C}-4(\delta 42.1)$ and from $26-\mathrm{H}_{3}(\delta 1.02)$ to $\mathrm{C}-3, \mathrm{C}-4, \mathrm{C}-5(\delta 25.5)$, and C-13 $(\delta$ $76.5)$ and the clear cross peaks from $5-\mathrm{H}_{2}(\delta 1.34,2.70)$ to $\mathrm{C}-13(\delta 78.0), 6-\mathrm{H}_{2}(\delta 2.28,1.78)$ to $\mathrm{C}-4(\delta$ $42.3)$, and $7-\mathrm{H}(\delta 4.38)$ to $\mathrm{C}-12(\delta 67.8)$ in $\mathrm{CDCl}_{3}$ supported that two cyclohexane rings (rings $\mathrm{B}$ and $\mathrm{C}$ ) are attached to ring A, covering partial structure I and III. The cross peak from $13-\mathrm{OH}(\delta 4.50)$ to $\mathrm{C}-4$ indicated the presence of a hydroxy group at quaternary C-13. (5) The cross peaks from 7-H to C-9 $(\delta$ $71.0)$ and $\mathrm{C}-11(\delta 58.9)$, from $11-\mathrm{H}$ to $\mathrm{C}-7(\delta 70.6)$ and $\mathrm{C}-12(\delta 67.0)$, from $9-\mathrm{H}$ to $\mathrm{C}-27(\delta 74.1), \mathrm{C}-28(\delta$ $16.7)$, and C-29 ( $\delta 28.2)$, from $10-\mathrm{H}$ to $\mathrm{C}-27$, from $28-\mathrm{H}_{3}(\delta 1.22)$ to $\mathrm{C}-9, \mathrm{C}-27$, and C-29, from $29-\mathrm{H}_{3}$ $(\delta 1.12)$ to $\mathrm{C}-9, \mathrm{C}-27$, and $\mathrm{C}-28$, and from $31-\mathrm{H}$ to $\mathrm{C}-10(\delta 70.1)$ and $\mathrm{C}-27$ showed the presence of a tetrahydropyran ring (ring D) and 1,3-dioxane ring (ring E), which includes a partial structure II. In addition, the cross peaks from $31-\mathrm{H}$ to $\mathrm{C}-34(\delta 137.4)$, from $33-\mathrm{H}$ to $\mathrm{C}-35(\delta 18.3)$ and $\mathrm{C}-36(\delta 25.0)$, from $35-\mathrm{H}_{3}(\delta 1.63)$ to $\mathrm{C}-33(\delta 122.5), \mathrm{C}-34$, and C-36, and from $36-\mathrm{H}_{3}(\delta 1.64)$ to C-33, C-34, and C-35 suggested that a 2-methyl-2-butene with partial structure V is bound to C-31 of ring E. Taking the molecular formula, the carbon chemical shifts and the degrees of unsaturation into consideration, two oxygen atoms should build two epoxy groups between C-38 and C-39 and between C-11 and C-12. Taken together, the planar structure of 2 was elucidated as shown in Figure 3a.

Table 1. Physicochemical properties of 1-3.

\begin{tabular}{cccc}
\hline & $\mathbf{1}$ & $\mathbf{2}$ & $\mathbf{3}$ \\
\hline Appearance & White powder & White powder & White powder \\
Molecular weight & 653 & 603 & 519 \\
Molecular formula & $\mathrm{C}_{37} \mathrm{H}_{51} \mathrm{NO}_{9}$ & $\mathrm{C}_{37} \mathrm{H}_{49} \mathrm{NO}_{6}$ & $\mathrm{C}_{32} \mathrm{H}_{41} \mathrm{NO}_{5}$ \\
HR-ESI-MS $(m / z)$ & $654.3642[\mathrm{M}+\mathrm{H}]^{+}$ & $604.3625[\mathrm{M}+\mathrm{H}]^{+}$ & $520.3067[\mathrm{M}+\mathrm{H}]^{+}$ \\
Calcd & $654.3637[\mathrm{M}+\mathrm{H}]^{+}$ & $604.3638[\mathrm{M}+\mathrm{H}]^{+}$ & $520.3063[\mathrm{M}+\mathrm{H}]^{+}$ \\
Found & $213(4.2), 248(4.3)$, & $230(3.5), 283(3.0)$ & $227(4.4), 280(3.7)$ \\
$\mathrm{UV}_{\lambda} \mathrm{CHax}_{\operatorname{man}}^{\mathrm{OH}_{\mathrm{OH}}(\log \varepsilon)}$ & $290(3.7)$ & $3449,2979,2930,1458$ & $3380,3004,2931,1681$ \\
$\mathrm{IR}_{\max }^{\mathrm{KBr}} \mathrm{cm}^{-1}$ & $3413,2977,2930,1718$ & $-4.0(\mathrm{t}=23)$ & $-27.8(\mathrm{t}=25)$ \\
{$[\alpha]_{\mathrm{D}}^{\mathrm{C}}\left(\mathrm{c}=0.1 \mathrm{CH}_{3} \mathrm{OH}\right)$} & $-16.6(\mathrm{t}=25)$ & &
\end{tabular}

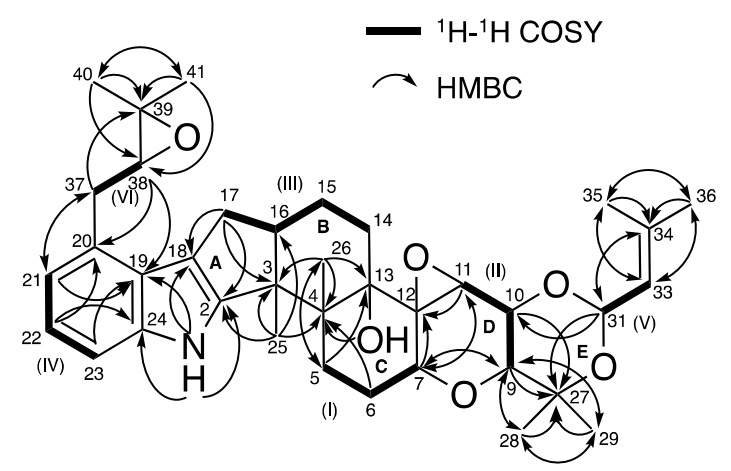

(a)

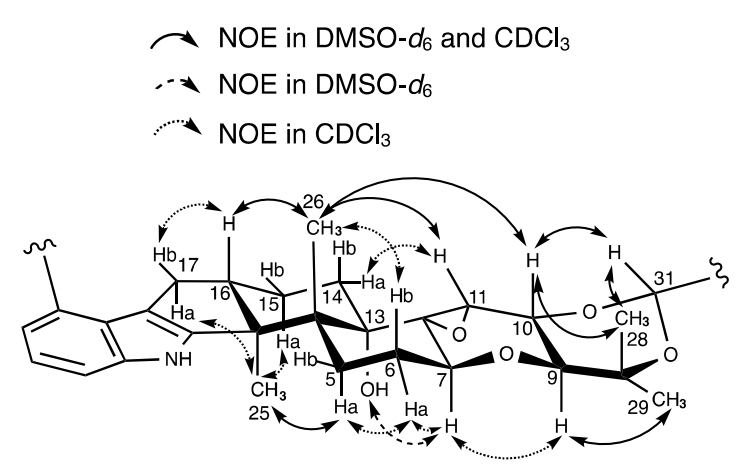

(b)

Figure 3. Structural elucidation of 2: (a) Key correlations in ${ }^{1} \mathrm{H}-{ }^{1} \mathrm{H}$ correlation spectroscopy (COSY) and heteronuclear multiple bond correlation (HMBC) spectra; (b) nuclear Overhauser effect spectroscopy (NOESY) experiments.

To elucidate the relative stereochemistry of 11 chiral carbons in $2,{ }^{1} \mathrm{H}^{-}{ }^{1} \mathrm{H}$ coupling constants and nuclear Overhauser effect spectroscopy (NOESY) experiments in DMSO- $d_{6}$ and $\mathrm{CDCl}_{3}$ were analyzed (Figure $3 b)$. The large coupling constant $(9.6 \mathrm{~Hz})$ between $9-\mathrm{H}$ and $10-\mathrm{H}$ indicated that they are in an axial position. In DMSO- $d_{6}$, nuclear Overhauser effect (NOE) correlations were observed between $25-\mathrm{H}_{3}$ and $5-\mathrm{H}_{\mathrm{a}}(\delta 2.42)$ and 13-OH and 7-H. In $\mathrm{CDCl}_{3}$, additional NOEs were observed between $25-\mathrm{H}_{3}$ $(\delta 1.27)$ and $15-\mathrm{H}_{\mathrm{a}}(\delta 1.90), 25-\mathrm{H}_{3}$ and $17-\mathrm{H}_{\mathrm{a}}(\delta 2.60), 5-\mathrm{H}_{\mathrm{a}}(\delta 2.70)$ and $6-\mathrm{H}_{\mathrm{a}}(\delta 2.28), 6-\mathrm{H}_{\mathrm{a}}$ and $7-\mathrm{H}(\delta$ 
4.38), and 7-H and 9- $\mathrm{H}(\delta 3.57)$. These data indicated that these protons were oriented in the same side of the plane of the consecutive ring system. In contrast, NOEs were observed between $16-\mathrm{H}$ and $26-\mathrm{H}_{3}, 10-\mathrm{H}$ and $26-\mathrm{H}_{3}$, and among $10-\mathrm{H}, 31-\mathrm{H}$, and $28-\mathrm{H}_{3}$ in DMSO- $d_{6}$, and between $16-\mathrm{H}(\delta 2.80)$ and $17-\mathrm{H}_{\mathrm{b}}(\delta 2.83), 6-\mathrm{H}_{\mathrm{b}}(\delta 1.78)$ and $26-\mathrm{H}_{3}(\delta 1.14)$ in $\mathrm{CDCl}_{3}$. The data indicated that these protons were present on the opposite side. Furthermore, NOE was observed between $11-\mathrm{H}(\delta 3.61)$ and $14-\mathrm{H}_{\mathrm{a}}$ ( $\delta 1.43)$ in $\mathrm{CDCl}_{3}$, suggesting that $11-\mathrm{H}$ was in the equatorial position. Taken together, the relative stereochemistry of 2 except for $C-38$ was elucidated to be $3 S^{*}, 4 R^{*}, 7 S^{*}, 9 S^{*}, 10 R^{*}, 11 R^{*}, 12 S^{*}, 13 S^{*}, 16 S^{*}$, and $31 S^{*}$.

Table 2. ${ }^{1} \mathrm{H}$ - and ${ }^{13} \mathrm{C}-\mathrm{NMR}$ chemical shifts of $1-3$ in DMSO- $d_{6}$.

\begin{tabular}{|c|c|c|c|c|c|c|c|}
\hline \multicolumn{8}{|c|}{ Terpendole N (1) ${ }^{a}$} \\
\hline Position & $\delta_{\mathrm{C}}{ }^{\mathrm{c}}$, type & $\delta_{\mathrm{H}}^{\mathrm{d}}($ multi, $J \mathrm{~Hz})$ & НМВС & Position & $\delta_{\mathrm{C}}{ }^{\mathrm{c}}$, type & $\delta_{\mathrm{H}}^{\mathrm{d}}(\mathrm{multi}, J \mathrm{~Hz})$ & НМВС \\
\hline $1-\mathrm{NH}$ & - & $10.08(\mathrm{~s})$ & $2,18,19,24$ & 18 & $76.8, \mathrm{C}$ & - & - \\
\hline 2 & $180.2, \mathrm{C}$ & - & - & $18-\mathrm{OH}$ & - & $5.72(\mathrm{~s})$ & 18,19 \\
\hline 3 & 74.6, C & - & - & 19 & $128.9, \mathrm{C}$ & - & - \\
\hline 3-OH & - & $3.74(\mathrm{~s})$ & $3,16,25$ & 20 & $136.7, \mathrm{C}$ & - & - \\
\hline 4 & $44.9, \mathrm{C}$ & - & - & 21 & $121.9, \mathrm{CH}$ & $6.81(\mathrm{~d}, 7.6)$ & 19,23 \\
\hline & & $1.15-1.21(\mathrm{~m})$ & \multirow[b]{2}{*}{4} & 22 & $128.8, \mathrm{CH}$ & $7.11(t, 7.6)$ & 20,24 \\
\hline 5 & $23.2, \mathrm{CH}_{2}$ & $1.92(\mathrm{~m})$ & & 23 & $107.5, \mathrm{CH}$ & $6.63(\mathrm{~d}, 7.6)$ & 19,21 \\
\hline \multirow[b]{2}{*}{6} & \multirow{2}{*}{$28.1, \mathrm{CH}_{2}$} & $1.32(\mathrm{~m})$ & \multirow{2}{*}{$4,7,12$} & 24 & 141.7, C & - & - \\
\hline & & $1.88(\mathrm{~m})$ & & 25 & $19.5, \mathrm{CH}_{3}$ & $1.08(\mathrm{~s})$ & 3,16 \\
\hline \multirow{2}{*}{7} & \multirow{2}{*}{$70.5, \mathrm{CH}$} & \multirow{2}{*}{$4.02(\mathrm{dd}, 10.2,7.4)$} & \multirow{2}{*}{$6,11,12$} & 26 & 16.7, $\mathrm{CH}_{3}$ & $0.59(\mathrm{~s})$ & $4,5,13$ \\
\hline & & & & 27 & $74, \mathrm{C}$ & - & - \\
\hline \multirow{2}{*}{9} & \multirow{2}{*}{$70.9, \mathrm{CH}$} & \multirow{2}{*}{$3.34(\mathrm{~d}, 9.6)$} & \multirow{2}{*}{$27,28,29$} & 28 & $16.7, \mathrm{CH}_{3}$ & $1.14(\mathrm{~s})$ & $9,27,29$ \\
\hline & & & & 29 & $28.3, \mathrm{CH}_{3}$ & $1.073(\mathrm{~s})$ & $9,27,28$ \\
\hline 10 & $70.1, \mathrm{CH}$ & $3.92(\mathrm{~d}, 9.6)$ & - & 31 & $92, \mathrm{CH}$ & $5.42(\mathrm{~d}, 6.4)$ & $10,27,34$ \\
\hline 11 & $59.1, \mathrm{CH}$ & 3.33 (br s) & $7,9,12$ & 33 & $122.5, \mathrm{CH}$ & $5.05($ br d, 6.4) & 35,36 \\
\hline 12 & $66.8, \mathrm{C}$ & - & - & 34 & $137.5, \mathrm{C}$ & - & - \\
\hline 13 & $75.9, \mathrm{C}$ & - & - & 35 & $18.4, \mathrm{CH}_{3}$ & $1.61(\mathrm{~d}, 1.2)$ & 34,36 \\
\hline $13-\mathrm{OH}$ & - & $4.18(\mathrm{~s})$ & $4,13,14$ & 36 & $25, \mathrm{CH}_{3}$ & $1.63(\mathrm{~s})$ & 34,35 \\
\hline \multirow[t]{2}{*}{14} & \multirow{2}{*}{$25.5, \mathrm{CH}_{2}$} & $0.81-0.90(\mathrm{~m})$ & \multirow{2}{*}{4} & \multirow{2}{*}{37} & \multirow{2}{*}{ 29.7, $\mathrm{CH}_{2}$} & $2.87(\mathrm{~m})$ & $19,20,21$, \\
\hline & & $1.04-1.08(\mathrm{~m})$ & & & & $3.03(\mathrm{~m})$ & 39 \\
\hline \multirow{2}{*}{15} & \multirow{2}{*}{ 23.7, $\mathrm{CH}_{2}$} & $1.10(\mathrm{~d}, 4.8)$ & 17 & 38 & $62.9, \mathrm{CH}$ & $3.02(\mathrm{~m})$ & 20 \\
\hline & & $1.27(\mathrm{~s})$ & 17 & 39 & $57.8, \mathrm{C}$ & - & - \\
\hline 16 & $37.5, \mathrm{CH}$ & $1.27-1.34(\mathrm{~m})$ & - & 40 & $18.9, \mathrm{CH}_{3}$ & $1.27(\mathrm{~s})$ & 41 \\
\hline 17 & 37.1, $\mathrm{CH}_{2}$ & $\begin{array}{c}1.68(\mathrm{dd}, 12.6,10.6) \\
2.29(\mathrm{~d}, 12.6)\end{array}$ & $2,3,15,18$ & 41 & 24.7, $\mathrm{CH}_{3}$ & $1.23(\mathrm{~s})$ & $38,39,40$ \\
\hline & & & Terpen & le O (2) ${ }^{a}$ & & & \\
\hline Position & $\delta_{\mathrm{C}}{ }^{\mathrm{c}}$, type & $\delta_{\mathrm{H}}^{\mathrm{d}}($ multi, $J \mathrm{~Hz})$ & НМВС & Position & $\delta_{C}{ }^{c}$, type & $\delta_{\mathrm{H}}^{\mathrm{d}}(\mathrm{multi}, J \mathrm{~Hz})$ & НMBC \\
\hline 1-NH & - & $10.69(\mathrm{~s})$ & $2,18,19,24$ & 18 & $114.3, \mathrm{C}$ & - & - \\
\hline 2 & $152.3, \mathrm{C}$ & - & - & $18-\mathrm{OH}$ & - & - & - \\
\hline 3 & $49.9, \mathrm{C}$ & - & - & 19 & 124.1, C & - & - \\
\hline $3-\mathrm{OH}$ & - & - & - & 20 & $128.0, \mathrm{C}$ & - & - \\
\hline 4 & $42.1, \mathrm{C}$ & - & - & 21 & $118.2, \mathrm{CH}$ & $6.71(\mathrm{~d}, 7.2)$ & 19,23 \\
\hline & $255 \mathrm{CH}_{3}$ & 1.67 (br d, 6.4) & & 22 & $119.5, \mathrm{CH}$ & $6.86(t, 7.6)$ & 20,24 \\
\hline 5 & $25.5, \mathrm{CH}_{2}$ & $2.42(\mathrm{br} \mathrm{d}, 6.4)$ & 26 & 23 & $110.1, \mathrm{CH}$ & $7.12(\mathrm{~d}, 8.0)$ & 19,21 \\
\hline 6 & $28.53, \mathrm{CH}_{2}$ & $2.12(\mathrm{br} \mathrm{m})$ & - & 24 & 139.7, C & - & - \\
\hline 6 & $20.00, \mathrm{CH}_{2}$ & $2.12(\mathrm{br} \mathrm{m})$ & - & 25 & $16, \mathrm{CH}_{3}$ & $1.16(\mathrm{~s})$ & $2,3,4$ \\
\hline 7 & $70.6, \mathrm{CH}$ & $4.26(\mathrm{t}, 8.8)$ & 9.11 & 26 & $18, \mathrm{CH}_{3}$ & $1.02(\mathrm{~s})$ & $3,4,5,13$ \\
\hline 7 & $70.6, \mathrm{CH}$ & $4.26(t, 8.8)$ & 9,11 & 27 & 74.1, C & - & - \\
\hline & $71 \mathrm{CH}$ & $3.40(\mathrm{~d}, 96)$ & 7.27 .28 .29 & 28 & 16.7, $\mathrm{CH}_{3}$ & $1.22(\mathrm{~s})$ & $9,27,29$ \\
\hline 9 & $71, \mathrm{CH}$ & $3.40(\mathrm{~d}, 9.6)$ & $7,27,28,29$ & 29 & $28.2, \mathrm{CH}_{3}$ & $1.12(\mathrm{~s})$ & $9,27,28$ \\
\hline 10 & $70.1, \mathrm{CH}$ & $4.04(\mathrm{~d}, 9.6)$ & 27 & 31 & $91.9, \mathrm{CH}$ & $5.50(\mathrm{~d}, 6.4)$ & $10,27,34$ \\
\hline 11 & $58.9, \mathrm{CH}$ & 3.50 (br. s) & $7,9,12$ & 33 & $122.5, \mathrm{CH}$ & $5.10(\mathrm{~d}, 6.4)$ & 35,36 \\
\hline 12 & $67.0, \mathrm{C}$ & - & - & 34 & $137.4, \mathrm{C}$ & - & - \\
\hline 13 & $76.5, \mathrm{C}$ & - & - & 35 & $18.3, \mathrm{CH}_{3}$ & $1.63(\mathrm{~d}, 0.8)$ & $33,34,36$ \\
\hline $13-\mathrm{OH}$ & - & $4.50(\mathrm{~s})$ & 4 & 36 & $25.0, \mathrm{CH}_{3}$ & $1.64(\mathrm{~s})$ & $33,34,35$ \\
\hline 14 & $28.38, \mathrm{CH}_{2}$ & $\begin{array}{l}1.46(\mathrm{br} \mathrm{m}) \\
1.52(\mathrm{br} \mathrm{s})\end{array}$ & - & 37 & $32.3, \mathrm{CH}_{2}$ & $\begin{array}{c}2.93(\mathrm{~m}) \\
3.01(\mathrm{dd}, 16,8.4)\end{array}$ & 21 \\
\hline & $203 \mathrm{CH}_{3}$ & 1.46 (br m) & - & 38 & $63.4, \mathrm{CH}$ & $2.93(\mathrm{~m})$ & 20,21 \\
\hline 15 & $20.3, \mathrm{CH}_{2}$ & 1.80 (br m) & - & 39 & $57.9, \mathrm{C}$ & - & - \\
\hline 16 & 49.6, $\mathrm{CH}$ & 2.71 (br m) & - & 40 & $18.7, \mathrm{CH}_{3}$ & $1.32(\mathrm{~s})$ & $38,39,41$ \\
\hline 17 & $28.58, \mathrm{CH}_{2}$ & $\begin{array}{l}2.45 \text { (br s) } \\
2.71 \text { (br m) }\end{array}$ & $2,3,18$ & 41 & 24.6, $\mathrm{CH}_{3}$ & $1.23(\mathrm{~s})$ & $38,39,40$ \\
\hline
\end{tabular}


Table 2. Cont.

\begin{tabular}{|c|c|c|c|c|c|c|c|}
\hline \multicolumn{8}{|c|}{ Terpendole P (3) ${ }^{b}$} \\
\hline Position & $\delta_{C}{ }^{c}$, type & $\delta_{\mathrm{H}}^{\mathrm{d}}($ multi, $J \mathrm{~Hz})$ & НМВС & Position & $\delta_{C}{ }^{c}$, type & $\delta_{\mathrm{H}}^{\mathrm{d}}$ (multi, $\left.J \mathrm{~Hz}\right)$ & НМВС \\
\hline 1-NH & - & $10.81(\mathrm{~s})$ & $2,18,19,24$ & 18 & $114.7, \mathrm{C}$ & - & - \\
\hline 2 & $150.6, \mathrm{C}$ & - & - & 19 & $124.1, \mathrm{C}$ & - & - \\
\hline 3 & $38.3, \mathrm{C}$ & - & - & 20 & $117.8, \mathrm{CH}$ & $7.26(\mathrm{~d}, 7.8)$ & 18,22 \\
\hline $3-\mathrm{OH}$ & - & - & - & 21 & $118.4, \mathrm{CH}$ & $6.88(\mathrm{td}, 7.8,1.2)$ & 19,23 \\
\hline 4 & $48.3, \mathrm{C}$ & - & - & 22 & $119.5, \mathrm{CH}$ & $6.93(\mathrm{td}, 7.8,1.2)$ & 20,24 \\
\hline \multirow{2}{*}{5} & \multirow{2}{*}{$27.9, \mathrm{CH}_{2}$} & \multirow{2}{*}{$2.05(\mathrm{~m})$} & \multirow{2}{*}{$3,4,7,13$} & 23 & $111.7, \mathrm{CH}$ & $7.24(\mathrm{~d}, 7.8)$ & 19,21 \\
\hline & & & & 24 & $140.1, \mathrm{C}$ & - & - \\
\hline \multirow{2}{*}{6} & \multirow{2}{*}{$28.2, \mathrm{CH}_{2}$} & \multirow{2}{*}{$1.75(\mathrm{~m}) 2.30(\mathrm{~m})$} & \multirow[b]{2}{*}{ - } & 25 & $16.2, \mathrm{CH}_{3}$ & 0.99 (s) & $2,3,4,16$ \\
\hline & & & & 26 & $18, \mathrm{CH}_{3}$ & $1.12(\mathrm{~s})$ & $3,4,5,13$ \\
\hline \multirow{2}{*}{7} & \multirow{2}{*}{$70.6, \mathrm{CH}$} & \multirow{2}{*}{$3.86(\mathrm{~m})$} & \multirow{2}{*}{9,12} & 27 & $76.9, \mathrm{C}$ & - & - \\
\hline & & & & 28 & $21.4, \mathrm{CH}_{3}$ & $1.17(\mathrm{~s})$ & $9,27,29$ \\
\hline 9 & $75.5 . \mathrm{CH}$ & $3.25(\mathrm{~d}, 9.0)$ & $7,11,27$ & 29 & $23.9, \mathrm{CH}_{3}$ & $1.16(\mathrm{~s})$ & $9,27,28$ \\
\hline$y$ & / & $0.20(u, 9.0)$ & 28,29 & \multirow{2}{*}{31} & \multirow{2}{*}{$58.1, \mathrm{CH}_{2}$} & $3.87(\mathrm{~m})$ & \multirow{2}{*}{$10,27,34$} \\
\hline 10 & $65.5, \mathrm{CH}$ & $3.89(\mathrm{~m})$ & - & & & $3.91(\mathrm{~m})$ & \\
\hline $10-\mathrm{OH}$ & - & $4.78(\mathrm{~d}, 4.2)$ & $9,10,11$ & 33 & $122.1, \mathrm{CH}$ & $5.18(\mathrm{dd}, 7.0,1.2)$ & 35,36 \\
\hline 11 & $63.1, \mathrm{CH}$ & $3.32(\mathrm{~s})$ & $9,10,12$ & 34 & $134.5, \mathrm{C}$ & - & - \\
\hline 12 & $62.9, \mathrm{C}$ & - & - & 35 & $17.7, \mathrm{CH}_{3}$ & $1.58(\mathrm{~s})$ & 34,36 \\
\hline 13 & $66.9, \mathrm{C}$ & - & - & 36 & $25.3, \mathrm{CH}_{3}$ & $1.65(\mathrm{~s})$ & $33,34,35$ \\
\hline 14 & $54.7, \mathrm{CH}$ & $3.19(\mathrm{~d}, 5.4)$ & 12,13 & & & & \\
\hline 15 & $24.5, \mathrm{CH}_{2}$ & $\begin{array}{l}2.02(\mathrm{~m}) \\
1.85(\mathrm{~m})\end{array}$ & 13,17 & & & & \\
\hline 16 & $45, \mathrm{CH}$ & $2.63(\mathrm{~m})$ & $2,3,4,18$ & & & & \\
\hline \multirow{2}{*}{17} & \multirow{2}{*}{ 26.7, $\mathrm{CH}_{2}$} & $2.17(\mathrm{~m})$ & \multirow{2}{*}{$2,3,15,18$} & & & & \\
\hline & & $2.62(\mathrm{~m})$ & & & & & \\
\hline
\end{tabular}

${ }^{a}{ }^{13} \mathrm{C}(100 \mathrm{MHz})$ and ${ }^{1} \mathrm{H}(400 \mathrm{MHz})$ spectra were taken on an NMR $400 \mathrm{MHz}$ spectrometer (Agilent). ${ }^{\text {b } 13} \mathrm{C}(150$ $\mathrm{MHz})$ and ${ }^{1} \mathrm{H}(600 \mathrm{MHz})$ spectra were taken on an NMR $600 \mathrm{MHz}$ spectrometer (Bruker). Chemical shifts are shown with reference to ${ }^{c}$ DMSO- $d_{6}$ as $\delta 39.5,{ }^{\mathrm{d}}$ DMSO- $d_{6}$ as $\delta 2.48$. Multiplicity of signals as follows: $\mathrm{s}=$ singlet, $\mathrm{d}=$ doublets, $\mathrm{dd}=$ double doublets, $\mathrm{t}=$ triplet, $\mathrm{m}=$ multi. Coupling constants $(\mathrm{Hz})$ were determined by the ${ }^{1} \mathrm{H}-{ }^{1} \mathrm{H}$ decoupling experiments.

\subsection{Structural Elucidation of New Terpendole N (1)}

The physicochemical properties of $\mathbf{1}$ are summarized in Table 1 . The molecular formula $\mathrm{C}_{37} \mathrm{H}_{51} \mathrm{NO}_{9}$ for 1 was assigned based on HR-ESIMS ( $m / z$, found 654.3637 , calcd 654.3642 for $\left.\mathrm{C}_{37} \mathrm{H}_{52} \mathrm{NO}_{9}[\mathrm{M}+\mathrm{H}]^{+}\right)$, indicating 13 degrees of unsaturation. Compound 1 had UV absorbance maxima at 213, 248, and $290 \mathrm{~nm}$, along with IR absorptions at 3413, 2977, 2930, and $1458 \mathrm{~cm}^{-1}$. The structure of 1 was then elucidated using NMR experiments (Figures S13-S18). The data of ${ }^{13} \mathrm{C}-\mathrm{NMR}$ and ${ }^{1} \mathrm{H}-\mathrm{NMR}$ in DMSO- $d_{6}$ are shown in Table 2. The ${ }^{13} \mathrm{C}$-NMR spectrum of $\mathbf{1}$ showed 37 resolved signals, which were classified into 8 methyl carbons, 6 methylene carbons, four $s p^{2}$ methine carbons, $7 s p^{3}$ methine carbons, $5 s p^{2}$ quaternary carbons, and $7 s p^{3}$ quaternary carbons by an analysis of HSQC data (Table 2 and Figure S14). The ${ }^{1} \mathrm{H}-\mathrm{NMR}$ spectrum of 1 showed 51 proton signals (Table 2 and Figure S13), which were classified into 8 methyl protons, 6 methylene protons, four $s p^{2}$ and $7 s p^{3}$ methine protons, one amine proton, and three hydroxy protons. The connectivity of proton and carbon atoms was established by HSQC (Table 2). Compared with the ${ }^{13} \mathrm{C}-\mathrm{NMR}$ spectra of $\mathbf{2}$, the chemical shift values of $\mathbf{1}$ at C-2, C-3, and C-18 were remarkably shifted, suggesting that 1 has one additional $s p^{2}$ and two additional $s p^{3}$ oxygenated carbons. From the ${ }^{13} \mathrm{C}-{ }^{1} \mathrm{H}$ long range couplings of ${ }^{2} \mathrm{~J}$ and ${ }^{3} \mathrm{~J}$ in the HMBC spectrum (Figure $4 \mathrm{a}$ and Figure S17), the cross peaks from $18-\mathrm{OH}(\delta 5.72)$ to oxygenated $\mathrm{C}-18(\delta 76.8)$ and aromatic $\mathrm{C}-19(\delta$ $128.9)$, and from $3-\mathrm{OH}(\delta 3.74)$ to oxygenated $\mathrm{C}-3(\delta 74.6), \mathrm{C}-16(\delta 37.5)$, and $\mathrm{C}-25(\delta 19.5)$ indicated that a hydroxy moiety was directly bound to $\mathrm{C}-18$ and C-3. Furthermore, the chemical shift value at C-2 ( $\delta$ 180.2) supported the presence of an amide group, which implied that $\mathbf{1}$ contains an indolinone moiety. Taken together, the planar structure of $\mathbf{1}$ was proposed as shown in Figure $4 a, b$, which fulfilled the molecular formula and degrees of unsaturation.

Relative stereochemistry of $\mathbf{1}$ was elucidated by analyses of ${ }^{1} \mathrm{H}_{-}{ }^{1} \mathrm{H}$ coupling constants and NOESY experiments. As shown in Figure 4c, the NOE correlations of $\mathbf{1}$ were very similar to those of $\mathbf{2}$. Consequently, the relative stereochemistry of 12 chiral carbons except for C-18 and C-38 of 1 was determined to be $3 S^{*}, 4 R^{*}, 7 S^{*}, 9 S^{*}, 10 R^{*}, 11 R^{*}, 12 S^{*}, 13 S^{*}, 16 S^{*}$, and $31 S^{*}$. 


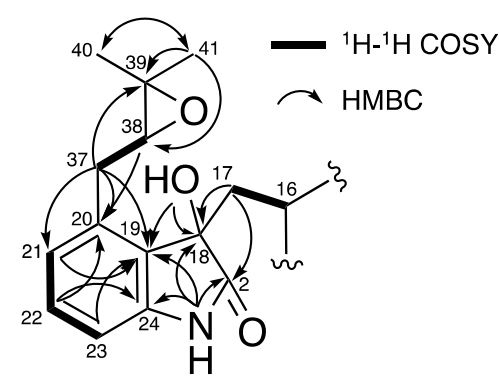

(a)

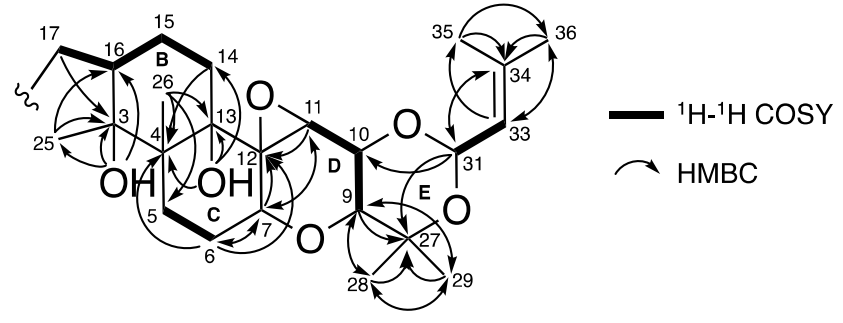

(b)

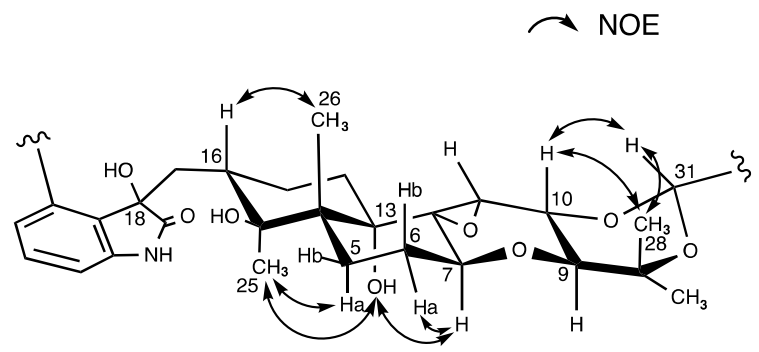

(c)

Figure 4. Structural elucidation of 1: (a,b) Key correlations in ${ }^{1} \mathrm{H}_{-}{ }^{1} \mathrm{H}$ COSY and HMBC spectra; (c) NOESY experiments.

\subsection{Structural Elucidation of New Terpendole P (3)}

The physicochemical properties of 3 are summarized in Table 1 . The molecular formula $\mathrm{C}_{32} \mathrm{H}_{41} \mathrm{NO}_{5}$ was determined based on HR-ESIMS ( $m / z$, found 520.3063, calcd 520.3067 for $\mathrm{C}_{32} \mathrm{H}_{42} \mathrm{NO}_{5}[\mathrm{M}+\mathrm{H}]^{+}$). Compound 3 had UV absorbance maxima at 227 and $280 \mathrm{~nm}$, along with IR absorptions at 3380, 3004, 2931, and $1681 \mathrm{~cm}^{-1}$ (Table 1). The structure of 3 was then elucidated using NMR experiments (Figures S19-S24). The data of ${ }^{13} \mathrm{C}-\mathrm{NMR}$ and ${ }^{1} \mathrm{H}-\mathrm{NMR}$ in DMSO- $d_{6}$ are shown in Table 3 . The ${ }^{13} \mathrm{C}-\mathrm{NMR}$ spectrum of 3 showed 32 resolved signals, which were classified into 6 methyl carbons, 5 methylene carbons, $5 s p^{2}$ methine carbons, $6 s p^{3}$ methine carbons, $5 s p^{2}$ and $5 s p^{3}$ quaternary carbons using HSQC experiments (Table 2 and Figure S20). The ${ }^{1} \mathrm{H}-\mathrm{NMR}$ spectrum of 3 showed 41 proton signals (Table 2 and Figure S19), which were classified into 6 methyl protons, 5 methylene protons, $5 s p^{2}$ and $6 s p^{3}$ methine protons, one amine proton, and one hydroxy proton. The connectivity of proton and carbon atoms was established using HSQC (Table 2). The ${ }^{13} \mathrm{C}$ chemical shifts of 3 were similar to these of terpendole $\mathrm{J}(\mathbf{1 1})[15]\left(\mathrm{C}_{32} \mathrm{H}_{43} \mathrm{NO}_{5}\right)$ except for $\mathrm{C}-14(\delta 54.7)$. From the ${ }^{13} \mathrm{C}-{ }^{1} \mathrm{H}$ long range couplings of ${ }^{2} J$ and ${ }^{3} \mathrm{~J}$ in the HMBC spectrum (Figure $5 \mathrm{a}$ and Figure S23), the position of these carbons was confirmed. Considering the different molecular formula between 3 and 10, the presence of an epoxide moiety was suggested between C-13 and C-14. Therefore, the structure of 3 was elucidated as shown in Figure 5a, which fulfilled the molecular formula and degrees of unsaturation. The relative stereochemistry of 10 chiral carbons of 3 was determined to be $3 S^{*}, 4 R^{*}, 7 S^{*}, 9 S^{*}, 10 R^{*}, 11 R^{*}, 12 S^{*}, 13 R^{*} 14 S^{*}$, and $16 R^{*}$ by NOE experiments in a similar way for $\mathbf{1}$ and $\mathbf{2}$ (Figure $5 b$ ). 
Table 3. Inhibitory activities of 1-12 on human sterol $O$-acyltransferase (SOAT) 1 and SOAT2 activities in cell-based assays.

\begin{tabular}{|c|c|c|c|}
\hline \multirow{2}{*}{ Compound. } & \multicolumn{2}{|c|}{$\mathrm{IC}_{50}(\mu \mathrm{M})^{\mathrm{a}}$} & \multirow{2}{*}{ SI $^{b}$ (Type) $^{c}$} \\
\hline & SOAT1 & SOAT2 & \\
\hline 1 & $>14$ & $>14$ & - \\
\hline 2 & 2.8 & 2.4 & +0.06 (dual) \\
\hline 3 & 5.9 & 6.9 & -0.06 (dual) \\
\hline $4^{d}$ & 0.67 & 0.24 & +0.45 (dual) \\
\hline $5^{d}$ & 6.12 & 0.073 & +1.92 (SOAT2) \\
\hline $6^{d}$ & 6.7 & 3.5 & +0.27 (dual) \\
\hline 7 & 2.0 & 2.2 & -0.04 (dual) \\
\hline 8 & 0.8 & 2.1 & -0.42 (dual) \\
\hline 9 & 6.8 & 1.8 & +0.57 (dual) \\
\hline 10 & $>18$ & $>18$ & - \\
\hline 11 & 18.6 & 10.7 & +0.24 (dual) \\
\hline $12^{\mathrm{e}}$ & 12 & 6.5 & +0.26 (dual) \\
\hline
\end{tabular}

${ }^{\mathrm{a}} \mathrm{n} \geqq 3 .{ }^{\mathrm{b}}$ Selectivity Index $=\log \left(\mathrm{IC}_{50}\right.$ for SOAT1/IC ${ }_{50}$ for SOAT2). ${ }^{\mathrm{c}}$ Type of inhibitors (Dual with $-1.0<\mathrm{SI}<+1.0$, SOAT1 with $\mathrm{SI} \leqq-1.0$, SOAT2 with $+1.0 \leqq$ SI. ${ }^{\mathrm{d}}$ Data from Ref. 13 . ${ }^{\mathrm{e}}$ Data from Ref. 18 (African green monkey SOAT1 and SOAT2-CHO cells).

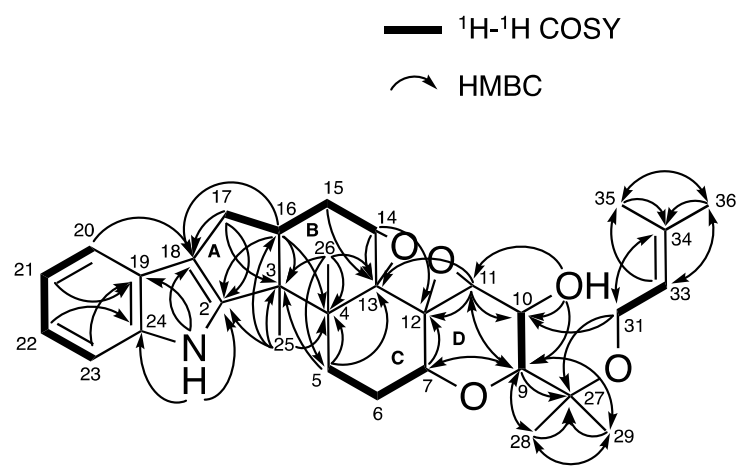

(a)

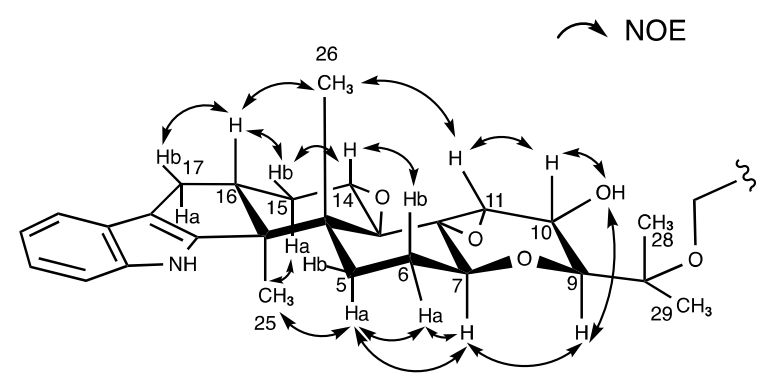

(b)

Figure 5. Structural elucidation of 3: (a) Key correlations in ${ }^{1} \mathrm{H}^{-1} \mathrm{H}$ COSY and HMBC spectra; (b) NOESY experiments.

\subsection{Structural Identification of Known Compounds 4-11}

Based on spectral data including ${ }^{1} \mathrm{H}-\mathrm{NMR},{ }^{13} \mathrm{C}-\mathrm{NMR}$, and MS, and the search results of SciFinder Scholar, the structures of 4-11 were identified as the known NK12838 (4), voluhemins A (5) and B (6), terpendoles C (7), D (8), L (9), and J (11), and tolypocladin A (10) [12,14-16].

\subsection{Inhibition of SOAT Isozymes Using SOAT1- and SOAT2-CHO Cells}

The human SOAT inhibitory activities of 1-11 were evaluated in accordance with our established method in cell-based assays using SOAT1/SOAT2-CHO cells [11,17]. As shown in Table 3, 2 and 3 containing an indole moiety inhibited both SOAT1 and SOAT2 activity to a similar extent $\left(\mathrm{IC}_{50}\right.$ values ranging from 2.4 to $6.9 \mu \mathrm{M}$ ), giving selectivity index (SI; $\log \left(\mathrm{IC}_{50}\right.$ for SOAT1/IC 50 for SOAT2)) values of +0.06 and -0.06 , respectively. Thus, we defined that 2 and 3 are dual-type SOAT inhibitors (Table 3) [13]. On the other hand, $\mathbf{1}$ containing an indolinone moiety showed no inhibitory activity against both SOAT isozymes $\left(\mathrm{IC}_{50} \mathrm{~s},>14 \mu \mathrm{M}\right)$. Compounds $\mathbf{1}-\mathbf{3}$ did not exert cytotoxic effects on these $\mathrm{CHO}$ cell lines even at $14 \mu \mathrm{M}$. 


\section{Discussion}

During our screening study for SOAT inhibitors, we have reported a series of fungal indole/indoline-containing di/sesquiterpenes; namely terpendoles produced by Albophoma yamanashiensis [14,15], sespendole (12, Figure 1) produced by Pseudobotrytis terrestris FKA-25 [18,19], and voluhemins by Volutella citrinella BF-0440 [13]. As described in the present study, a total of 11 terpendole congeners (1-11) were isolated from the voluhemin-producing fungus. Herein, the SOAT inhibitory activity ( $\mathrm{IC}_{50}$ value) and selectivity (SI value) toward SOAT1 and SOAT2 isozymes of these compounds in cell-based assays are summarized in Table 3. Those of $\mathbf{1 2}$ are also added to Table 3.

The most common structure from 1-12 and diverse moieties R1 to R6 are illustrated in Figure 6 to discuss the SARs. (1) Ring systems: 5 (12), $6(\mathbf{3}, \mathbf{8}$, and 11), and $7(\mathbf{2}, \mathbf{4}, \mathbf{5}, \mathbf{6}, \mathbf{7}$, and 9) consecutive rings including an indole/indoline maintain SOAT inhibitory activity. Compound 1, which has opened ring A, lost SOAT inhibitory activity. These data indicated that 5-7 consecutive ring systems are important for exhibiting SOAT inhibitory activity. (2) R1 and R2; comparison among compounds 2, 4, 5, 6, 7, and 9; compounds 3, 8, and 11; and 12 indicated that the presence of an isoprenyl-derived moiety at R1 and R2 is not essential for SOAT inhibition. (3) R3 and R4; compounds with an indoline containing a hydroxyl group at R3 and R4 (4 and 6) maintained SOAT inhibitory activity, indicating that both hydroxy indoline and indole-type compounds exhibit SOAT inhibition. (4) R5; comparison between 4 and 6 revealed that the presence of a proton at R5 enhances SOAT inhibitory activities (both SOAT1 and SOAT2) approximately 10-fold. (5) R6; comparison between 8 and 11 showed that R6 markedly prefers a proton (8) to a hydroxyl group (11) for more potent SOAT inhibition (both SOAT1 and SOAT2, approximately 30- to 40-fold). Compound 3 with an epoxy group between C-13 and C-14 partially covering R6 showed an intermediate inhibitory activity. (6) R7; comparison between compounds (3, 8, and 11) and 10 strongly suggested that the presence of a free hydroxyl group at R7 loses SOAT inhibitory activity.

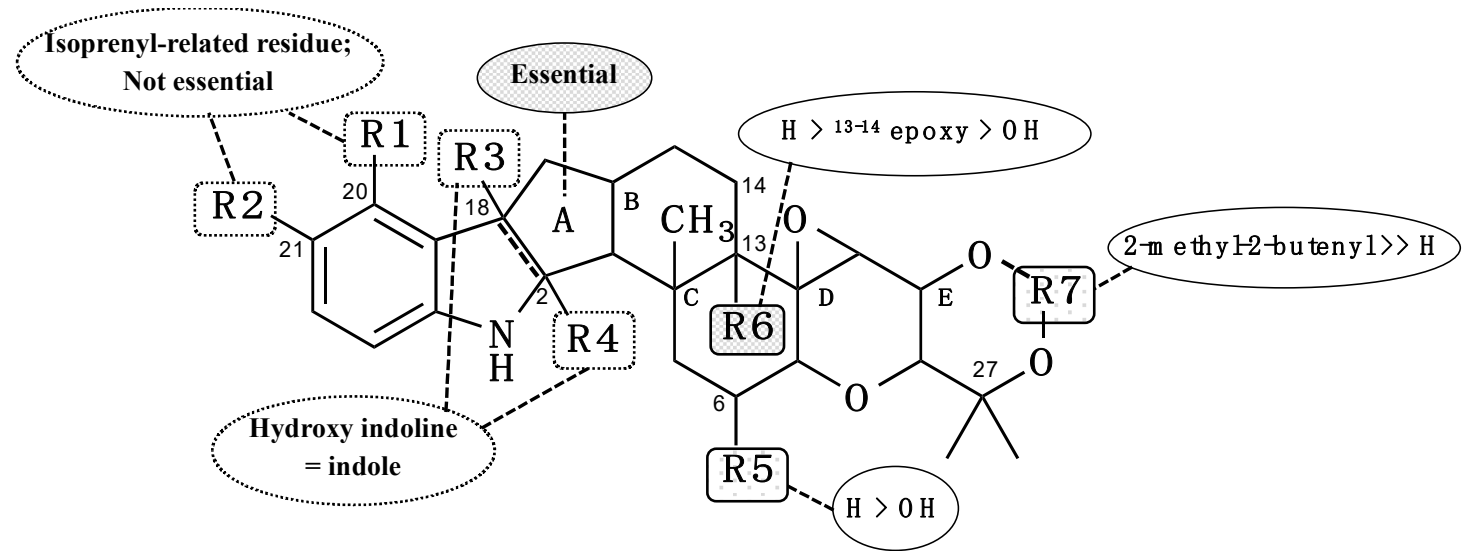

Figure 6. Structure-activity relationships of terpendole congeners for SOAT inhibitory activity.

Importantly, most terpendole congeners are intrinsically dual-type SOAT inhibitors, whereas only voluhemin B (5) exhibited SOAT2 selective inhibition. This finding indicated that the presence of a methoxy moiety at R4 is important for SOAT2 selectivity.

The structure of SOAT localized in the endoplasmic reticulum membrane had not been defined. Very recently, three research groups have just reported the structure of human-SOAT1 using cryo-electron microscopy [20-22]. Because SOAT1 and SOAT2 share extensive sequence homology, the structural properties of SOAT2 will be also elucidated in the near future. Accordingly, we will explain the SAR on a molecular basis and the selectivity of SOAT inhibitors (dual-type, SOAT1-selective or SOAT2-selective ones) toward SOAT isozymes. 


\section{Materials and Methods}

\subsection{General}

Various NMR spectra were obtained using the NMR System $400 \mathrm{MHz}$ spectrometer (Agilent Technologies, Santa Clara, CA, USA) and $600 \mathrm{MHz}$ spectrometer (Bruker, Karlsruhe, Germany). MS analysis was performed using the AccuTOF LC-plus JMS-T100LP system (JEOL, Tokyo, Japan). Optical rotations were measured using a digital polarimeter (DIP-1000; JASCO, Tokyo, Japan). UV spectra were recorded on a spectrophotometer (8453 UV-visible spectrophotometer; Agilent Technologies). IR spectra were recorded on a Fourier transform IR spectrometer (FT-710; Horiba Ltd., Kyoto, Japan).

\subsection{Materials}

$\left[1{ }^{14} \mathrm{C}\right]$ Oleic acid $\left(1.85 \mathrm{GBqmmol}^{-1}\right)$ was purchased from PerkinElmer (Waltham, MA, USA). Fetal bovine serum was purchased from Biowest (Nuaille, France). Geneticin (G-418 sulfate) was purchased from Merck (Burlington, MA, USA). MEM vitamin and penicillin $\left(10,000\right.$ units $\left.\mathrm{mL}^{-1}\right)$ /streptomycin $\left(10,000 \mathrm{mg} \mathrm{mL}^{-1}\right)$ solution were purchased from Invitrogen (Carlsbad, CA, USA). Ham's F-12 medium was purchased from Nacalai Tesque (Kyoto, Japan). Plastic microplates (48-well) were purchased from Corning (Corning, NY, USA).

\subsection{Fermentation and Isolation}

The fermentation procedure for the BF-0440 strain was performed based on a previous report [13]. A loop-full of strain was inoculated and then cultured with shaking for 3 days at $27^{\circ} \mathrm{C}$ in $100 \mathrm{~mL}$ of seed medium $\left(2.0 \%\right.$ glucose, $0.20 \%$ yeast extract, $0.050 \% \mathrm{MgSO}_{4} \cdot 7 \mathrm{H}_{2} \mathrm{O}, 0.50 \%$ polypeptone, $0.10 \% \mathrm{KH}_{2} \mathrm{PO}_{4}$ and $0.10 \%$ agar; $\mathrm{pH} 6.0$ ) in a $500 \mathrm{~mL}$ Erlenmeyer flask to obtain a seed culture. The seed culture $(10 \mathrm{~mL})$ was inoculated into a $1000 \mathrm{~mL}$ culture box containing $50 \mathrm{~g}$ of production medium (50 g of brown rice, $5 \mathrm{~mL}$ of the following solution; $2.4 \% \mathrm{PDB}, 0.50 \% \mathrm{MgSO}_{4} \cdot 7 \mathrm{H}_{2} \mathrm{O}, 0.50 \% \mathrm{~K}_{2} \mathrm{HPO}_{4}$ and $0.50 \%$ $\left.\mathrm{Mg}_{3}\left(\mathrm{PO}_{4}\right)_{2} \cdot 8 \mathrm{H}_{2} \mathrm{O}\right)$. Fermentation was carried out at $27{ }^{\circ} \mathrm{C}$ for 14 days in static conditions.

Culture broth was extracted with $70 \% \mathrm{EtOH}(2.5 \mathrm{~L})$. After concentration to remove EtOH, the aqueous solution was extracted with EtOAc $(900 \mathrm{~mL})$. The organic layer was collected and EtOAc was evaporated to give crude extract (brown material, $2.5 \mathrm{~g}$ ). This crude extract was applied to an ODS column (114 g, i.d. $45 \times 200 \mathrm{~mm})$ and eluted stepwise with $40 \%$ aq $\mathrm{CH}_{3} \mathrm{CN}, 60 \%$ aq $\mathrm{CH}_{3} \mathrm{CN}$, $80 \%$ aq $\mathrm{CH}_{3} \mathrm{CN}$, and $100 \% \mathrm{CH}_{3} \mathrm{CN}$ solutions $(600 \mathrm{~mL}$ each, fractionated into two). All fractions were concentrated in vacuo and the remaining water layers were extracted with EtOAc. The EtOAc layers of these fractions were collected and evaporated to dryness. Voluhemins A (4) and B (5) were purified from fraction $80 \%-1$, as reported in detail previously [13]. Fraction $60 \%-2$ (brown material, $249 \mathrm{mg}$ ) was subjected to preparative high-performance liquid chromatography (HPLC; column, Pegasil ODS SP100 i.d. $20 \times 250 \mathrm{~mm}$; mobile phase, $60 \%$ aq $\mathrm{CH}_{3} \mathrm{CN}$ isocratic; flow rate, $6.0 \mathrm{~mL} \mathrm{~min}^{-1}$; detection, UV at $210 \mathrm{~nm}$ ). In these conditions, NK12838 (6) [12] and terpendole N (1) were eluted as peaks with retention times of 27 and 29 min, respectively. Purification from fraction $80 \%-2$ (brown material, $214 \mathrm{mg}$ ) by preparative HPLC (column, Pegasil ODS SP100 i.d. $20 \times 250 \mathrm{~mm}$; mobile phase, $78 \%$ aq $\mathrm{CH}_{3} \mathrm{CN}$ isocratic; flow rate, $6.0 \mathrm{~mL} \mathrm{~min}^{-1}$; detection, $\mathrm{UV}$ at $210 \mathrm{~nm}$ ) allowed isolation of three peaks, terpendole $\mathrm{O}$ (2) eluted at $23 \mathrm{~min}$, terpendole C (7) [14] at $24 \mathrm{~min}$, and a third peak at $26 \mathrm{~min}$. The third peak was, however, found to be a mixture of related compounds from proton NMR analyses. This mixture was also obtained from fraction 100\%-1 along with terpendoles C (7) [14], D (8) [14], and L (9) [15], and tolypocladin A (10) [16]. By preparative HPLC (column, Pegasil ODS SP100 i.d. $20 \times 250 \mathrm{~mm}$; mobile phase, 35-min linear gradient $90-95 \%$ aq $\mathrm{CH}_{3} \mathrm{CN}$; flow rate, $6.0 \mathrm{~mL}$ $\min ^{-1}$; detection, UV at $\left.210 \mathrm{~nm}\right), 10,7$, the mixture, 8, and 9 were eluted at 16, 18, 22, 31, and $35 \mathrm{~min}$, respectively. The mixture was finally separated in different HPLC conditions (column, Develosil C30 i.d. $20 \times 250 \mathrm{~mm}$; mobile phase, $92 \%$ aq $\mathrm{CH}_{3} \mathrm{CN}$ isocratic; flow rate, $6.0 \mathrm{~mL} \mathrm{~min}{ }^{-1}$; detection, $\mathrm{UV}$ at $210 \mathrm{~nm}$ ) to yield a new terpendole $\mathrm{P}$ (3) and a known terpendole J (11) [15] eluted as peaks at 22 and 
$23 \mathrm{~min}$, respectively. All of these peaks were collected and concentrated to dryness to give $\mathbf{1}(2.1 \mathrm{mg})$, $2(21.6 \mathrm{mg}), 3(2.7 \mathrm{mg}), 6$ (46.6 mg), 7 (29.7 mg and $15.7 \mathrm{mg}$ from $80 \%-2$ and $100 \%-1$, respectively), $\mathbf{8}(8.3 \mathrm{mg}), \mathbf{9}(6.8 \mathrm{mg}), \mathbf{1 0}(3.8 \mathrm{mg})$ and $\mathbf{1 1}(1.6 \mathrm{mg})$ as white powders.

\subsection{Cell Culture}

CHO cells (AC29 cells, SOAT-deficient cells) expressing the SOAT1 or SOAT2 genes from human were cultured using a previously described method [17].

\subsection{Assay for SOAT Activity in SOAT1- and SOAT2-CHO Cells}

Assays for human SOAT1 and SOAT2 activities using SOAT1- and SOAT2-CHO cells were performed using our established method [11,17]. Briefly, SOAT1- or SOAT2-CHO cells $\left(1.25 \times 10^{5}\right.$ cells in $250 \mu \mathrm{L}$ of medium) were cultured in a 48 -well plastic microplate and allowed to recover at $37^{\circ} \mathrm{C}$ overnight in $5 \% \mathrm{CO}_{2}$. At least $80 \%$ confluent cells were used for assays. Following overnight recovery, a test sample (in $2.5 \mu \mathrm{L}$ methanol) and $\left[1-{ }^{14} \mathrm{C}\right]$ oleic acid (in $5 \mu \mathrm{L} 10 \% \mathrm{EtOH} / \mathrm{PBS}, 1 \mathrm{nmol}, 1.85 \mathrm{kBq}$ ) were added to each culture. After a 6-h incubation at $37{ }^{\circ} \mathrm{C}$ in $5 \% \mathrm{CO}_{2}$, medium was removed, and the cells in each well were washed twice with PBS. Cells were lysed by adding $0.25 \mathrm{~mL}$ of $10 \mathrm{mM}$ Tris- $\mathrm{HCl}$ ( $\mathrm{pH} 7.5$ ) containing $0.1 \%(w / v)$ sodium dodecyl sulfate, and $\left[{ }^{14} \mathrm{C}\right] \mathrm{CE}$ was analyzed using a FLA-7000 analyzer (Fuji Film). In this cell-based assay, $\left[{ }^{14} \mathrm{C}\right] \mathrm{CE}$ was produced by the reaction of SOAT1 or SOAT2. SOAT inhibitory activity $(\%)$ is defined as $\left(\left[1-{ }^{14} \mathrm{C}\right] \mathrm{CE}\right.$-drug/ $\left[{ }^{14} \mathrm{C}\right] \mathrm{CE}$-control $) \times 100$. The $\mathrm{IC}_{50}$ value is defined as the drug concentration causing a $50 \%$ inhibition of biological activity.

Supplementary Materials: The following are available online, Figures S1-S24: NMR spectra of 1-3, Table S1: NMR chemical shifts of $\mathbf{2}$ in $\mathrm{CDCl}_{3}$.

Author Contributions: H.T., K.K., T.O.; conceived and designed the experiments. E.A.A.N., A.A.; performed and analyzed the experiments. E.A.A.N., K.K., H.T.; wrote the paper. All authors have read and agreed to the published version of the manuscript.

Funding: This work was financially supported by JSPS KAKENHI Grant numbers 26253009 (Grant-in-Aid for Scientific Research (A)) (HT), 18KK0219 (Fund for the Promotion of Joint International Research (Fostering Joint International Research (B)) (HT), 18K06555 (Grant-in-Aid for Scientific Research (C)) (TO), 19K16320 (Grant-in-Aid for Young Scientists) (KK), the Takeda Science Foundation (HT), and MEXT Scholarship (EAA).

Acknowledgments: We thank to Noriko Sato and Kenichiro Nagai (Graduate School of Pharmaceutical Sciences, Kitasato University) for the measurements of NMR spectra and MS data. We express sincere thanks to the late L.L. Rudel (Wake Forest University, Winston-Salem, NC, USA) for kindly providing the SOAT1-CHO and SOAT2-CHO cells and always encouraging our study on SOAT inhibitors.

Conflicts of Interest: The authors declare no conflict of interest.

\section{References}

1. Feher, M.; Schmidt, J.M. Property Distributions: Differences between drugs, natural products, and molecules from combinatorial chemistry. J. Chem. Inf. Comput. Sci. 2003, 43, 218-227. [CrossRef]

2. Chang, C.C.; Huh, H.Y.; Cadigan, K.M.; Chang, T.Y. Molecular cloning and functional expression of human acyl-coenzyme A:cholesterol acyltransferase cDNA in mutant Chinese hamster ovary cells. J. Biol. Chem. 1993, 268, 20747-20755.

3. Anderson, R.A.; Joyce, C.; Davis, M.; Reagan, J.W.; Clark, M.; Shelness, G.S.; Rudel, L.L. Identification of a form of acyl-CoA:cholesterol acyltransferase specific to liver and intestine in nonhuman primates. J. Biol. Chem. 1998, 273, 26747-26754. [CrossRef]

4. Cases, S.; Novak, S.; Zheng, Y.W.; Myers, H.M.; Lear, S.R.; Sande, E.; Welch, C.B.; Lusis, A.J.; Spencer, T.A.; Krause, B.R.; et al. ACAT-2, a second mammalian acyl-CoA:cholesterol acyltransferase. Its cloning, expression, and characterization. J. Biol. Chem. 1998, 273, 26755-26764. [CrossRef]

5. Oelkers, P.; Behari, A.; Cromley, D.; Billheimer, J.T.; Sturley, S.L. Characterization of two human genes encoding acyl coenzyme A:cholesterol acyltransferase-related enzymes. J. Biol. Chem. 1998, 273, 26765-26771. [CrossRef] 
6. Rudel, L.L.; Lee, R.G.; Cockman, T.L. Acyl coenzyme A: Cholesterol acyltransferase types 1 and 2 : Structure and function in atherosclerosis. Curr. Opin. Lipidol. 2001, 12, 121-127. [CrossRef] [PubMed]

7. Chang, T.Y.; Chang, C.C.Y.; Lin, S.; Yu, C.; Li, B.L.; Miyazaki, A. Roles of acyl-coenzyme A: Cholesterol acyltransferase-1 and -2. Curr. Opin. Lipidol. 2001, 12, 289-296. [CrossRef]

8. Willner, E.L.; Tow, B.; Buhman, K.K.; Wilson, M.; Sanan, D.A.; Rudel, L.L.; Farese, R.V., Jr. Deficiency of acyl CoA:cholesterol acyltransferase 2 prevents atherosclerosis in apolipoprotein E-deficient mice. Proc. Natl. Acad. Sci. USA 2003, 100, 1262-1267. [CrossRef] [PubMed]

9. Buhman, K.K.; Accad, M.; Novak, S.; Choi, R.S.; Wong, J.S.; Hamilton, R.L.; Turley, S.; Farese, R.V. Resistance to diet-induced hypercholesterolemia and gallstone formation in ACAT2-deficient mice. Nat. Med. 2000, 6, 1341-1347. [CrossRef] [PubMed]

10. Alger, H.M.; Brown, J.M.; Sawyer, J.K.; Kelley, K.L.; Shah, R.; Wilson, M.D.; Willingham, M.C.; Rudel, L.L. Inhibition of acyl-coenzyme A:cholesterol acyltransferase 2 (ACAT2) prevents dietary cholesterol-associated steatosis by enhancing hepatic triglyceride mobilization. J. Biol. Chem. 2010, 285, 14267-14274. [CrossRef]

11. Ohshiro, T.; Rudel, L.L.; Ōmura, S.; Tomoda, H. Selectivity of microbial acyl-CoA:Cholesterol acyltransferase Inhibitors toward Isozymes. J. Antibiot. 2007, 60, 43-51. [CrossRef] [PubMed]

12. Tsuchiya, K.; Sukenaga, Y.; Kuroiwa, S. Physiological active substance NK12838, its manufacturing method, and a purpose. Jpn Kokai Tokkyo Koho 2002, 2002-363184.

13. Ohshiro, T.; Morita, H.; Nur, E.A.A.; Hosoda, K.; Uchida, R.; Tomoda, H. Voluhemins, new inhibitors of sterol O-acyltransferase, produced by Volutella citrinella BF-0440. J. Antibiot. 2020, in press. [CrossRef] [PubMed]

14. Huang, X.H.; Nishida, H.; Tomoda, H.; Tabata, N.; Shiomi, K.; Yang, D.J.; Takayanagi, H.; Ōmura, S. Terpendoles, novel ACAT inhibitors produced by Albophoma yamanashiensis. II. Structure elucidation of terpendoles A., B., C and D. J. Antibiot. 1995, 48, 5-11. [CrossRef]

15. Tomoda, H.; Tabata, N.; Yang, D.J.; Takayanagi, H.; Omura, S. Terpendoles, novel ACAT inhibitors produced by Albophoma yamanashiensis. III. Production, isolation and structure elucidation of new components. J. Antibiot. 1995, 48, 793-804. [CrossRef] [PubMed]

16. Xu, L.-L.; Hai, P.; Zhang, S.-B.; Xiao, J.-F.; Gao, Y.; Ma, B.-J.; Fu, H.-Y.; Chen, Y.-M.; Yang, X.-L. Prenylated indole diterpene alkaloids from a mine-soil-derived Tolypocladium sp.. J. Nat. Prod. 2019, 82, 221-231. [CrossRef] [PubMed]

17. Lada, A.T.; Davis, M.; Kent, C.; Chapman, J.; Tomoda, H.; Omura, S.; Rudel, L.L. Identification of ACAT1and ACAT2-specific inhibitors using a novel, cell-based fluorescence assay: Individual ACAT uniqueness. J. Lipid Res. 2004, 45, 378-386. [CrossRef] [PubMed]

18. Uchida, R.; Kim, Y.P.; Namatame, I.; Tomoda, H.; Ōmura, S. Sespendole, a new inhibitor of lipid droplet synthesis in macrophages, produced by Pseudobotrytis terrestris FKA-25. J. Antibiot. 2006, 59, 93-97. [CrossRef]

19. Uchida, R.; Kim, Y.P.; Nagamitsu, T.; Tomoda, H.; Ōmura, S. Structure elucidation of fungal sespendole, an inhibitor of lipid droplet synthesis in macrophages. J. Antibiot. 2006, 59, 338-344. [CrossRef]

20. Guan, C.; Niu, Y.; Chen, S.-C.; Kang, Y.; Wu, J.X.; Nishi, K.; Chang, C.C.Y.; Chang, T.-Y.; Luo, T.; Chen, L. Structural insights into the inhibition mechanism of human sterol $O$-acyltransferase 1 by a competitive inhibitor. Nat. Commun. 2020, 11, 2478. [CrossRef]

21. Qian, H.; Zhao, X.; Yan, R.; Yao, X.; Gao, S.; Sun, X.; Du, X.; Yang, H.; Wong, C.C.L.; Yan, N. Structural basis for catalysis and substrate specificity of human ACAT1. Nature 2020, 581, 333-338. [CrossRef] [PubMed]

22. Long, T.; Sun, Y.; Hassan, A.; Qi, X.; Li, X. Structure of nevanimibe-bound tetrameric human ACAT1. Nature 2020, 581, 339-343. [CrossRef] [PubMed]

Sample Availability: Samples of the compounds are not available from the authors. 